\title{
Vocabulary performance of students with and without difficulties learning to read and write
}

\author{
Cláudia da Silva \\ https://orcid.org/0000-0003-3091-8448 \\ Patrícia do Valle Alves ${ }^{2}$ \\ https://orcid.org/0000-0002-3537-7903
}

Universidade Federal Fluminense - UFF, Departamento de Formação Específica em Fonoaudiologia, Nova Friburgo, Rio de Janeiro, Brasil.

2 Universidade Federal Fluminense - UFF, Curso de Graduação em Fonoaudiologia, Nova Friburgo, Rio de Janeiro, Brasil.

Research conduct at the Instituto de Saúde de Nova Friburgo pelo Departamento de Formação Específica em Fonoaudiologia - FEF - da Universidade Federal Fluminense - UFF, Nova Friburgo, Rio de Janeiro, Brazil.

Conflict of interests: Nonexistent

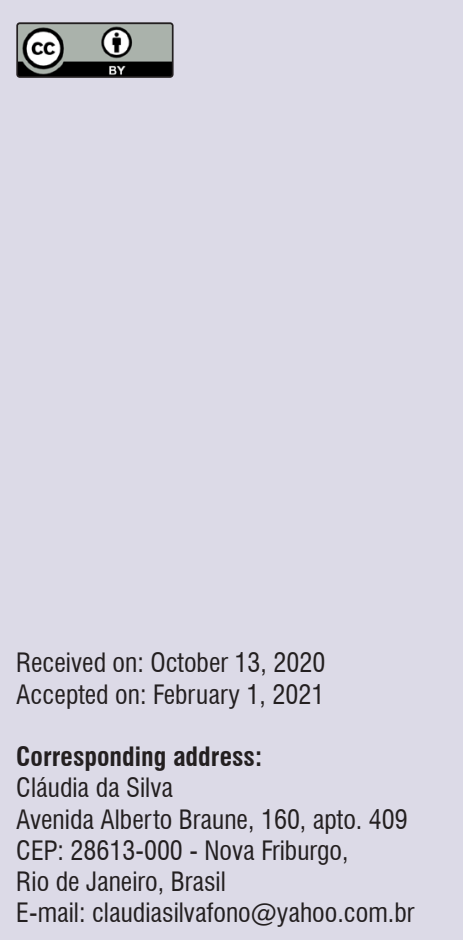

\section{ABSTRACT}

Purpose: to compare vocabulary performances and verify the lexical competence of students with and without difficulties learning to read and write.

Methods: 93 first-grade students were divided into Group I (50 students without difficulties) and Group II (43 students with difficulties learning to read and write). They were administered the Child Language Test focusing on vocabulary. The analysis considered aspects of usual word designation, non-designation, and substitution process. The data analysis was conducted with the Mann-Whitney test, with a p-value $\leq 0.05$.

Results: there were significant performances in the comparison between the groups in all the conceptual fields analyzed. There was no significance for either group regarding the conceptual fields of Foods, Furniture and Appliances, Places, and Professions in non-designation; regarding Means of Transportation in substitution processes; regarding Toys and Musical Instruments in both non-designation and substitution processes. Group I had higher means than Group II in usual word designation, and lower ones in non-designation and substitution processes.

Conclusion: students with difficulties learning to read and write had greater difficulties in usual word designation, as well as higher error indexes in substitution processes and non-designation, which reveals a deficient vocabulary concerning lexical access in comparison with students without difficulties.

Keywords: Vocabulary; Learning; Language; Child Development; Speech, Language and Hearing Sciences 


\section{INTRODUCTION}

In child development, particularly in the preschool stage, the children are expected to develop and further expand their preexisting vocabulary - which is gradually acquired, depending on intrinsic aspects related to cognitive skills and neurodevelopment. There are also the extrinsic interferences related to socioenvironmental factors associated with stimulation, family, and educational aspects and socioeconomic factors ${ }^{1,2}$.

According to the acquisition process, by 12 months old, approximately, the first words begin to be formed. This is a period when the children begin producing meaningfully. From 22 to 36 months old, there is an increase in the acquisition rate, characterized by the "vocabulary boom" - i.e., a striking increase in vocabulary that can form a lexicon of up to 500 words. Thus, vocabulary acquisition has development peaks during childhood and takes place naturally until 16 years old, a period of intense school exposure. Following this age, one enters the adult phase, in which the expansion is directly related to the personal interests and the environment to which the person belongs $\mathrm{s}^{3 \cdot 5}$.

The vocabulary can be divided into two main processes, namely: the receptive (which is what the person understands) and the expressive (what the person emits). According to the typical language development, the child's acquisition of receptive vocabulary precedes that of expressive vocabulary and therefore has a more significant size. The child, then, understands more words than they can express ${ }^{2,6}$. During the vocabulary acquisition process, making mistakes is common because of the attempt to name words that may not belong to the child's lexicon. These mistakes are called substitution errors, which the child tends to overcome as their lexical development advances ${ }^{7}$.

By around 5 years old, the child's vocabulary begins to resemble that of an adult in terms of the number of words in everyday use - which does not mean they are the same because the words they choose to use are different. This information is relevant, as it provides parameters to know what vocabulary size to expect in a child's production and to compare vocabulary data to the characteristics identified in ongoing language learning ${ }^{8}$.

The vocabulary is the starting point of oral language acquisition. Consequently, difficulties acquiring it can be a determining factor to changes in language production and reception. Children with such difficulty do not develop the language the same way those without this history do. Hence, they reveal language difficulties that impair oral communication and that can extend to written language learning ${ }^{6,7,9}$.

Knowing words means not only knowing their meaning but also how to use them in a sentence. Vocabulary acquisition and morphosyntactic development are correlated, as vocabulary expansion makes it possible to organize more complex sentences, with more elements on them. This way, there is an implicit awareness of the part of speech to which a word belongs because the difficulty acquiring vocabulary also affects other language dominions, such as the syntactic and morphological ones ${ }^{2,4,5,10}$.

It is not enough, in vocabulary test analysis, for a child to only name words; they must categorize them and give them meaning. It is much more important to understand the child's behavior when something has been presented to them than to only quantify the number of correct productions. The naming tests involving the identification of stimuli but not associating it with its functionality aim to identify the base process in vocabulary acquisition. Such tests generally assume that children who cannot name words hardly progress to more complex learning - for instance, knowing the function and meaning of a word and its applicability in skills such as written language $e^{1,3,4}$.

The cognitive influence associated with environmental stimuli actively participates in child development. As the child develops in cognitive and linguistic terms and learns to use the vocabulary they acquired, they will have better access to the lexicon, using it with greater amplitude and depth throughout their development ${ }^{11,12}$. These aspects will reflect the ongoing language development in further learning, including that of reading and writing ${ }^{13}$.

For reading to be effectively acquired, two processes - decoding and comprehension - need to occur efficiently as well, because both processes are related to the lexicon. The words stored in the lexicon that make up the receptive vocabulary, with an established meaning and concept, are essentially useful to reading comprehension. Understanding a text requires access to previous knowledge, which will be associated with new information coming from interpreting the text they read. Hence, mastering vocabulary and its amplitude make it easier to make inferences about the text and efficiently understand $\mathrm{it}^{2,14,15}$.

Vocabulary development directly influences not only comprehension but also decoding, since the person needs to search the lexicon to read a word. The information processing speed to access the lexicon 
influences reading speed and accuracy. In other words, the more efficient the access and use of the lexicon in the context, the better the reading performance standards ${ }^{16,17}$.

Further in this reciprocal development approach, the greater the child's reading habit, the better their lexical competence - i.e., the knowledge of vocabulary and the ability to use it, understanding lexical and grammatical elements of which the language is made. These elements that start in oral language and later are representative in written language give access to words and to forming sentences and texts ${ }^{8}$.

Studies indicate that children with vocabulary development deficits have unsatisfactory results in narrative composition tests because not being able to apply and structure the words in the sentences is a crucial factor in writing acquisition. The interrelationship between syntactic and morphological awareness and lexical level shows there may be difficulties organizing sentences in oral communication - which, as a consequence, are transferred to written language because they are successively developed ${ }^{4,10,18,19}$.

Thus, the hypothesis of this study is based on the use of lexical competence in terms of access to vocabulary on the part of first graders. It is expected that differences will be identified between students with and without difficulties learning to read and write - which is a valuable marker that can help the intervention in students in the written language acquisition process, addressing future deficits.

Given the above, this study aimed to compare the vocabulary performance of schoolchildren with and without difficulties learning to read and write to verify their lexical competence.

\section{METHODS}

Before beginning it, this study was submitted to the Research Ethics Committee (REC) of the Universidade Federal Fluminense - UFF (Fluminense Federal University), Nova Friburgo, RJ, Brazil, and approved under protocol number 1.800 .368 . The parents or guardians of all the participants signed the informed consent form, while the participants themselves signed the assent form, complying with the ethical research development criteria.

This study sample comprised 93 first graders from a public elementary school, aged 5 years and 9 months to 6 years and 5 months, divided into:
- Group I (Gl): with 50 students who had no difficulties learning to read and write -27 females and 23 males.

- Group II (GII): with 43 students who had difficulties learning to read and write -18 females and 25 males.

The difference in the number of participants between $\mathrm{Gl}$ and GII was due to sample loss during collection, caused by their dropping out of school, changing to another school, or giving up from the research. The students were matched for the grade; they belonged to the same school, and the collection was carried out with morning and afternoon students.

The inclusion criteria used to select the sample were the signed consent and assent forms, students with visual and auditory acuity and normal cognitive performance, and students actively enrolled for classes in either the morning or afternoon in accordance with the time of day the collection was made. The exclusion criteria encompassed not signing the consent and assent forms, students diagnosed with language development disorder, phonological deviation, or other genetic or neurological syndromes. The specific information on the children's development was verified in the participants' school records.

The schoolchildren in Gl and Gll were indicated by their teachers based on satisfactory and unsatisfactory performance in two consecutive bimesters - the performance parameter was the comparison of data in the class group. The data were collected at school in the second term after the principal had approved and the teachers had agreed to it.

The assessment instrument was the ABFW Child Language Test, covering phonology, vocabulary, fluency, and pragmatics ${ }^{20}$, with a focus on vocabulary. This test was chosen because it verifies the schoolchildren's lexical competence, as an initial investigation approach to their productions and access to vocabulary. The ABFW is a child language test, indicated for those 2 to 12 years old. The vocabulary assessment has nine conceptual fields, sequentially presented in the following order: Clothing (1), Animals (2), Foods (3), Means of Transportation (4), Furniture and Appliances (5), Professions (6), Places (7), Shapes and Colors (8), Toys and Musical Instruments (9).

The test was individually administered at school, in a 30-to-40-minute session on average. The school provided a classroom to be used at the same time of day the child regularly attended classes. All stimuli that might distract the children - such as posters, maps, 
pictures, calendars, and so on - were removed from the room. All the participants of the research were submitted to the assessment in the same manner, following the categorical sequence of the conceptual fields for naming and figure presentation, as proposed by the instrument.

The vocabulary naming process was analyzed based on the percentage of correct answers out of a total of $100 \%$ in each category. The schoolchildren assessed in this study were 5 years and 9 months to 6 years and 5 months old. As the sample was closer to 6 years old, all the schoolchildren's vocabulary performance in the nine conceptual fields was matched to the 6 -year-old age group, following the analysis criterion proposed in the test.

The vocabulary verification was analyzed in relation to the normal language development for usual word designation (UWD) when the answer correctly represented the target-word; non-designation (ND), when it was not named; and substitution process (SP), when the answer was not exact, involving para-synonyms, hypernyms, hyponyms, and co-hyponyms. The specific substitution error classification was not used in this study, only the total production quantitative value. The analyses were meant to characterize the significance resources used by the students when exposed to a target-picture and asked to name it immediately.

The results were statistically analyzed with the Statistical Package for the Social Sciences (SPSS), version 20.0, based on the number of correct answers presented by Gl and Gll. The Mann-Whitney statistical test was used to verify possible differences when comparing the groups. The $5 \%(\leq 0.05)$ significance level was used, and the statistically significant results were marked with an asterisk (*).

\section{RESULTS}

The results were presented in tables according to the distribution of the mean, standard deviation, minimum, and maximum values, and percentages. Table 1 shows the statistical distribution comparing the performance of $\mathrm{Gl}$ and Gll students regarding Clothing and Animals. There was a significant performance for both in all the variables analyzed - i.e., usual word designation (UWD), non-designation (ND), and substitution process (SP). Regarding both Clothing and Animals, GI had higher means than GII in UWD. In ND and SP, the result was the opposite, with lower means for $\mathrm{Gl}$ and higher ones for Gll. This suggests a performance pattern in both conceptual fields analyzed.

Table 2 presents the performance distribution of $\mathrm{Gl}$ and Gll students regarding Foods and Means of Transportation. Significant performances were observed in UWD (with a higher mean for GI) and SP (with lower means for GI than for GII) regarding Foods. As for Means of Transportation, there was significance in UWD (also with a higher mean for GI than for GII) and ND (in which Gl had a lower mean than GII). 
Table 1. Data distribution comparing Groups I and II regarding the conceptual fields of Clothing and Animals

\begin{tabular}{|c|c|c|c|c|c|c|c|c|c|c|}
\hline Variable & Groups & $n$ & Mean & SD & Min & Max & $\begin{array}{c}\text { 25th } \\
\text { percent }\end{array}$ & Median & $\begin{array}{c}\text { 75th } \\
\text { percent }\end{array}$ & $\mathrm{p}$-value \\
\hline \multirow{3}{*}{$\begin{array}{l}\text { Clothing } \\
\text { \%UWD }\end{array}$} & $\mathrm{Gl}$ & 50 & 99.00 & 3.03 & 90.00 & 100.00 & 100.00 & 100.00 & 100.00 & \multirow{3}{*}{$<0.001^{*}$} \\
\hline & GII & 43 & 87.00 & 16.26 & 60.00 & 100.00 & 72.50 & 95.00 & 100.00 & \\
\hline & Total & 93 & 95.57 & 10.45 & 60.00 & 100.00 & 100.00 & 100.00 & 100.00 & \\
\hline \multirow{4}{*}{$\begin{array}{c}\text { Clothing } \\
\% N D\end{array}$} & $\mathrm{Gl}$ & 50 & 0.60 & 2.40 & 0.00 & 10.00 & 0.00 & 0.00 & 0.00 & \multirow{3}{*}{$0.019^{*}$} \\
\hline & Gll & 43 & 4.00 & 7.54 & 0.00 & 20.00 & 0.00 & 0.00 & 7.50 & \\
\hline & Total & 93 & 1.57 & 4.71 & 0.00 & 20.00 & 0.00 & 0.00 & 0.00 & \\
\hline & $\mathrm{Gl}$ & 50 & 0.40 & 1.98 & 0.00 & 10.00 & 0.00 & 0.00 & 0.00 & \multirow{3}{*}{$<0.001^{*}$} \\
\hline \multirow[t]{2}{*}{ Clothing \%SP } & GII & 43 & 9.00 & 14.11 & 0.00 & 40.00 & 0.00 & 0.00 & 20.00 & \\
\hline & Total & 93 & 2.86 & 8.54 & 0.00 & 40.00 & 0.00 & 0.00 & 0.00 & \\
\hline \multirow{3}{*}{$\begin{array}{l}\text { Animals } \\
\% \text { UWD }\end{array}$} & $\mathrm{Gl}$ & 50 & 99.47 & 2.27 & 87.00 & 100.00 & 100.00 & 100.00 & 100.00 & \multirow{3}{*}{$<0.001^{*}$} \\
\hline & Gll & 43 & 90.47 & 14.79 & 53.00 & 100.00 & 81.68 & 100.00 & 100.00 & \\
\hline & Total & 93 & 96.89 & 8.98 & 53.00 & 100.00 & 100.00 & 100.00 & 100.00 & \\
\hline \multirow{4}{*}{$\begin{array}{c}\text { Animals } \\
\% N D\end{array}$} & $\mathrm{Gl}$ & 50 & 0.27 & 1.33 & 0.00 & 7.00 & 0.00 & 0.00 & 0.00 & \multirow{3}{*}{$0.007^{*}$} \\
\hline & GII & 43 & 4.01 & 8.76 & 0.00 & 33.00 & 0.00 & 0.00 & 5.03 & \\
\hline & Total & 93 & 1.34 & 5.03 & 0.00 & 33.00 & 0.00 & 0.00 & 0.00 & \\
\hline & $\mathrm{Gl}$ & 50 & 0.27 & 1.88 & 0.00 & 13.00 & 0.00 & 0.00 & 0.00 & \multirow{3}{*}{$0.002^{*}$} \\
\hline \multirow[t]{2}{*}{ Animals \%SP } & GII & 43 & 5.33 & 11.16 & 0.00 & 40.00 & 0.00 & 0.00 & 4.88 & \\
\hline & Total & 93 & 1.71 & 6.49 & 0.00 & 40.00 & 0.00 & 0.00 & 0.00 & \\
\hline
\end{tabular}

* Mann-Whitney test, $p$-value $\leq 0.05$

Captions: SD: standard deviation; percent: percentile; UWD: usual word designation; ND: non-designation; SP: substitution process

Table 2. Data distribution comparing Groups I and II regarding the conceptual fields of Foods and Means of Transportation

\begin{tabular}{ccccccccccc}
\hline Variable & Group & $\mathbf{n}$ & Mean & SD & Min & Max & $\begin{array}{c}\text { 25th } \\
\text { percent }\end{array}$ & Median & $\begin{array}{c}\text { 75th } \\
\text { percent }\end{array}$ & p-value \\
\hline & Gl & 50 & 97.46 & 4.44 & 87.00 & 100.00 & 93.30 & 100.00 & 100.00 & $0.006^{*}$ \\
Foods \%UWD & Gll & 43 & 89.67 & 13.42 & 53.00 & 100.00 & 86.70 & 93.30 & 100.00 & \\
& Total & 93 & 95.24 & 8.73 & 53.00 & 100.00 & 93.30 & 100.00 & 100.00 & \\
& Gl & 50 & 2.13 & 4.14 & 0.00 & 13.00 & 0.00 & 0.00 & 1.65 & 0.355 \\
Foods \%ND & Gll & 43 & 4.67 & 7.83 & 0.00 & 20.00 & 0.00 & 0.00 & 11.65 & \\
& Total & 93 & 2.86 & 5.51 & 0.00 & 20.00 & 0.00 & 0.00 & 6.63 & \\
& Gl & 50 & 0.40 & 1.61 & 0.00 & 7.00 & 0.00 & 0.00 & 0.00 & $0.001^{*}$ \\
Foods \%SP & Gll & 43 & 5.67 & 8.73 & 0.00 & 27.00 & 0.00 & 0.00 & 13.30 & \\
& Total & 93 & 1.91 & 5.34 & 0.00 & 27.00 & 0.00 & 0.00 & 0.00 & \\
Means of & Gl & 50 & 87.62 & 9.69 & 63.60 & 100.00 & 81.80 & 90.90 & 90.90 & $0.013^{*}$ \\
Transportation & Gll & 43 & 79.98 & 12.39 & 54.50 & 90.90 & 74.98 & 81.80 & 90.90 & \\
\%UWD & Total & 93 & 85.44 & 11.00 & 54.50 & 100.00 & 81.80 & 90.90 & 90.90 & \\
Means of & Gl & 50 & 1.09 & 2.99 & 0.00 & 9.00 & 0.00 & 0.00 & 0.00 & $0.006^{*}$ \\
Transportation & Gll & 43 & 5.46 & 8.54 & 0.00 & 27.00 & 0.00 & 0.00 & 9.10 & \\
\%ND & Total & 93 & 2.34 & 5.51 & 0.00 & 27.00 & 0.00 & 0.00 & 0.00 & \\
Means of & Gl & 50 & 11.28 & 9.65 & 0.00 & 36.40 & 6.83 & 9.10 & 18.20 & 0.324 \\
Transportation & Gll & 43 & 14.57 & 13.01 & 0.00 & 45.50 & 9.10 & 9.10 & 18.20 & \\
\%SP & Total & 93 & 12.22 & 10.72 & 0.00 & 45.50 & 9.10 & 9.10 & 18.20 & \\
\hline
\end{tabular}

* Mann-Whitney test, $p$-value $\leq 0.05$

Captions: SD: standard deviation; percent: percentile; UWD: usual word designation; ND: non-designation; SP: substitution process 
Regarding Furniture and Appliances, and Professions there was a statistical significance in the comparison between GI and GII in UWD and SP in the two conceptual fields. Regarding both, GI had higher means than GII in UWD and lower means in SP.

Table 3. Data distribution comparing Groups I and II regarding the conceptual fields of Furniture and Appliances, and Professions

\begin{tabular}{ccccccccccc}
\hline Variable & Group & $\mathbf{n}$ & Mean & SD & Min & Max & $\begin{array}{c}\text { 25th } \\
\text { percent }\end{array}$ & Median & $\begin{array}{c}\text { 75th } \\
\text { percent }\end{array}$ & p-value \\
\hline Furniture/ & Gl & 50 & 91.08 & 6.08 & 75.00 & 100.00 & 87.50 & 91.70 & 95.80 & $<0.001^{*}$ \\
Appliances & GIl & 43 & 73.96 & 12.60 & 45.80 & 100.00 & 66.70 & 75.00 & 82.28 & \\
\%UWD & Total & 93 & 86.19 & 11.43 & 45.80 & 100.00 & 82.28 & 87.50 & 95.80 & \\
Furniture/ & Gl & 50 & 7.42 & 6.15 & 0.00 & 25.00 & 3.08 & 8.30 & 12.50 & 0.265 \\
Appliances & GIl & 43 & 9.79 & 8.14 & 0.00 & 33.30 & 4.20 & 8.30 & 12.50 & \\
\%ND & Total & 93 & 8.09 & 6.80 & 0.00 & 33.30 & 4.10 & 8.30 & 12.50 & \\
Furniture/ & Gl & 50 & 1.50 & 2.89 & 0.00 & 13.00 & 0.00 & 0.00 & 4.20 & $<0.001^{*}$ \\
Appliances & GIl & 43 & 16.26 & 10.97 & 0.00 & 33.00 & 6.28 & 16.70 & 25.00 & \\
\%SP & Total & 93 & 5.72 & 9.17 & 0.00 & 33.00 & 0.00 & 0.00 & 8.30 & \\
Professions & Gl & 50 & 80.80 & 15.37 & 40.00 & 100.00 & 70.00 & 80.00 & 90.00 & $0.001^{*}$ \\
\%UWD & GIl & 43 & 64.50 & 18.49 & 30.00 & 100.00 & 50.00 & 60.00 & 80.00 & \\
& Total & 93 & 76.14 & 17.80 & 30.00 & 100.00 & 70.00 & 80.00 & 90.00 & \\
Professions & Gl & 50 & 7.00 & 10.74 & 0.00 & 40.00 & 0.00 & 0.00 & 10.00 & 0.223 \\
\%ND & GIl & 43 & 12.00 & 16.42 & 0.00 & 60.00 & 0.00 & 10.00 & 17.50 & \\
& Total & 93 & 8.43 & 12.70 & 0.00 & 60.00 & 0.00 & 0.00 & 10.00 & \\
Professions & Gl & 50 & 12.20 & 11.66 & 0.00 & 40.00 & 0.00 & 10.00 & 20.00 & \multirow{2}{*}{$0.006^{*}$} \\
$\% S P$ & GIl & 43 & 23.50 & 16.31 & 0.00 & 60.00 & 10.00 & 30.00 & 30.00 & \\
\hline
\end{tabular}

* Mann-Whitney test, p-value $\leq 0.05$

Captions: SD: standard deviation; percent: percentile; UWD: usual word designation; ND: non-designation; SP: substitution process

The statistical analysis for Places revealed significance in UWD (with higher means for GI than for GII) and SP (with higher means for Gll than for Gl). As for Shapes and Colors, all the variables were significant, with a higher mean for GI in UWD and lower means for
Gl than for GII in ND and SP. And regarding Toys and Musical Instruments, there was a significance only in UWD, with higher means for GI in comparison with the performance of Gll. 
Table 4. Data distribution comparing Groups I and II regarding the conceptual fields of Places, Shapes and Colors, and Toys and Musical Instruments

\begin{tabular}{|c|c|c|c|c|c|c|c|c|c|c|}
\hline Variable & Group & n & Mean & SD & Min & Max & $\begin{array}{c}\text { 25th } \\
\text { percent }\end{array}$ & Median & 75th percent & $\mathrm{p}$-value \\
\hline \multirow{3}{*}{ Places \%UWD } & $\mathrm{Gl}$ & 50 & 89.51 & 12.12 & 42.00 & 100.00 & 83.30 & 91.70 & 100.00 & \multirow{3}{*}{$<0.001^{*}$} \\
\hline & Gll & 43 & 70.84 & 22.06 & 33.00 & 92.00 & 52.08 & 79.15 & 91.70 & \\
\hline & Total & 93 & 84.17 & 17.62 & 33.00 & 100.00 & 81.23 & 91.70 & 93.78 & \\
\hline \multirow{3}{*}{ Places \%ND } & $\mathrm{Gl}$ & 50 & 4.16 & 10.14 & 0.00 & 50.00 & 0.00 & 0.00 & 2.08 & \multirow{3}{*}{0.119} \\
\hline & Gll & 43 & 11.67 & 19.77 & 0.00 & 67.00 & 0.00 & 0.00 & 20.83 & \\
\hline & Total & 93 & 6.31 & 13.87 & 0.00 & 67.00 & 0.00 & 0.00 & 8.30 & \\
\hline \multirow{3}{*}{ Places \%SP } & Gl & 50 & 6.33 & 7.06 & 0.00 & 25.00 & 0.00 & 8.30 & 8.30 & \multirow{3}{*}{$0.009^{*}$} \\
\hline & Gll & 43 & 17.50 & 16.87 & 0.00 & 58.00 & 2.08 & 12.50 & 31.22 & \\
\hline & Total & 93 & 9.52 & 11.81 & 0.00 & 58.00 & 0.00 & 8.30 & 10.48 & \\
\hline \multirow{3}{*}{$\begin{array}{c}\text { Shapes and Colors } \\
\% \text { UWD }\end{array}$} & $\mathrm{Gl}$ & 50 & 96.20 & 8.05 & 70.00 & 100.00 & 100.00 & 100.00 & 100.00 & \multirow{3}{*}{$<0.001^{*}$} \\
\hline & Gll & 43 & 78.50 & 14.24 & 50.00 & 100.00 & 70.00 & 80.00 & 90.00 & \\
\hline & Total & 93 & 91.14 & 12.92 & 50.00 & 100.00 & 80.00 & 100.00 & 100.00 & \\
\hline \multirow{3}{*}{$\begin{array}{c}\text { Shapes and Colors } \\
\% N D\end{array}$} & $\mathrm{Gl}$ & 50 & 2.80 & 7.01 & 0.00 & 30.00 & 0.00 & 0.00 & 0.00 & \multirow{3}{*}{$0.003^{*}$} \\
\hline & GIl & 43 & 10.50 & 13.17 & 0.00 & 40.00 & 0.00 & 5.00 & 20.00 & \\
\hline & Total & 93 & 5.00 & 9.74 & 0.00 & 40.00 & 0.00 & 0.00 & 10.00 & \\
\hline \multirow{3}{*}{$\begin{array}{c}\text { Shapes and Colors } \\
\% \mathrm{SP}\end{array}$} & $\mathrm{Gl}$ & 50 & 1.00 & 4.63 & 0.00 & 30.00 & 0.00 & 0.00 & 0.00 & \multirow{3}{*}{$<0.001^{\star}$} \\
\hline & GII & 43 & 10.50 & 13.56 & 0.00 & 40.00 & 0.00 & 5.00 & 25.00 & \\
\hline & Total & 93 & 3.71 & 9.20 & 0.00 & 40.00 & 0.00 & 0.00 & 0.00 & \\
\hline \multirow{3}{*}{$\begin{array}{l}\text { Toys and Musical } \\
\text { Instruments } \\
\text { \%UWD }\end{array}$} & $\mathrm{Gl}$ & 50 & 93.44 & 10.42 & 54.50 & 100.00 & 90.90 & 100.00 & 100.00 & \multirow{3}{*}{$0.003^{*}$} \\
\hline & GII & 43 & 83.15 & 16.24 & 36.40 & 100.00 & 72.70 & 86.35 & 97.73 & \\
\hline & Total & 93 & 90.50 & 13.11 & 36.40 & 100.00 & 81.80 & 90.90 & 100.00 & \\
\hline \multirow{3}{*}{$\begin{array}{l}\text { Toys and Musical } \\
\text { Instruments \%ND }\end{array}$} & $\mathrm{Gl}$ & 50 & 4.67 & 9.04 & 0.00 & 36.70 & 0.00 & 0.00 & 9.10 & \multirow{3}{*}{0.093} \\
\hline & GII & 43 & 8.19 & 11.38 & 0.00 & 36.30 & 0.00 & 0.05 & 15.93 & \\
\hline & Total & 93 & 5.68 & 9.81 & 0.00 & 36.70 & 0.00 & 0.00 & 9.10 & \\
\hline \multirow{3}{*}{$\begin{array}{l}\text { Toys and Musical } \\
\text { Instruments \%SP }\end{array}$} & $\mathrm{Gl}$ & 50 & 2.07 & 4.36 & 0.00 & 18.20 & 0.00 & 0.00 & 0.00 & \multirow{3}{*}{0.119} \\
\hline & Gll & 43 & 8.21 & 16.14 & 0.00 & 63.60 & 0.00 & 0.00 & 9.10 & \\
\hline & Total & 93 & 3.82 & 9.64 & 0.00 & 63.60 & 0.00 & 0.00 & 2.28 & \\
\hline
\end{tabular}

* Mann-Whitney test, $\mathrm{p}$-value $\leq 0.05$

Captions: SD: standard deviation; percent: percentile; UWD: usual word designation; ND: non-designation; SP: substitution process

\section{DISCUSSION}

The data were discussed based on the lexical competence performance results, aiming to compare the performance of first-grade students with and without difficulties in this process. To achieve this goal, their expressive vocabulary was analyzed in terms of usual word designation (UWD), non-designation (ND), and substitution process (SP) regarding nine conceptual fields.

Regarding Clothing and Animals, the Gl schoolchildren's performance had a higher mean than those in GII in UWD. According to the results, the GI schoolchildren stood out in the task, returning a better performance in information processing and lexical retrieval for the naming task. The schoolchildren with difficulties learning to read and write had lower results in ND and
SP - i.e., a higher non-naming and substitution index -, suggesting a higher prevalence of semantic approximation, difficulty accessing the lexicon and/or limited vocabulary when presented to less frequent stimuli.

The change in language acquisition characterized by a slower and/or limited lexical development explains the low performance in expressive vocabulary assessments, especially when high-frequency words are evoked ${ }^{16}$. Thus, lexical processing is a strong indicator of language acquisition disorders which reflects directly on the school learning process to decode stimuli when reading $8,16,21$.

Regarding Shapes and Colors, it can be inferred from the analysis of the groups that the Gl students had better performance means in all the parameters analyzed. There was a similar configuration in this 
conceptual field and in Clothing and Animals - in which all the values analyzed were significant, indicating higher means for GI. In these three conceptual fields, both groups behaved similarly, that is, higher means in UWD and higher means for GIl regarding ND and SP.

The behavior revealed in these means may be related to the higher frequency of the words presented in these three categories in relation to those in other categories - as the frequency is a determining factor for lexical acquisition, storage, and retrieval. Hence, since these are usual words in different social contexts, such stimuli can be more consolidated in the schoolchildren's lexicon, influencing similar performances ${ }^{1,22}$.

Vocabulary development is a complex process that depends on social and economic factors and is constantly influenced by the environment where the child lives. It also depends on processing semanticlexical associations and phonological restrictions ${ }^{21}$. Children with changes in phonological processing, difficulties composing executive functions (such as planning, sequencing, and organization), or sensory limitations tend to have difficulties acquiring and expanding their vocabulary, as well as giving meaning to different semantic categories. In this context, the more usual the word, the more successful the child will be in retrieving and contextualizing the information ${ }^{11,18,23}$.

Children with difficulties learning to read and write sometimes have changes in oral language development and/or acquisition, which can worsen the reading and writing difficulties. Recent studies indicate a close relationship between changes in oral language that interfere with information processing. Some of these changes stand out, including difficulties processing phonological cues, distinguishing sound pairs (/p/ and /b/, /f/ and /v/, and so forth), distinguishing words and sound sequences (rhyme and alliteration) 4,13,24. $^{\text {. }}$

Along with these difficulties, the literature complements the literacy process with characteristics that suggest not relating letter/sound and difficulties retaining the letters of the alphabet in sequence and at random. Consequently, it mentions errors when forming words and manipulating simple segments in the structure of words and sentences ${ }^{21}$. Thus, when there is a change in language, the shorter the lexical extension (i.e., the smaller the vocabulary amplitude), the greater the likelihood of the child having impairments when formally learning to read and write ${ }^{10,25}$.

Regarding Foods, Furniture and Appliances, Professions, and Places the Gl students had higher means than GIl in UWD, suggesting better information processing. On the other hand, Gll had higher means than $\mathrm{Gl}$ in SP, with a greater difference between the means obtained in Furniture and Appliances, and Places. This performance indicates that the schoolchildren with difficulties learning to read and write have deficits in information access because it is not yet consolidated.

Children's behavior may include word approximation regarding these three semantic fields, in which they do not name the pictures precisely because of a semantic deficiency; then, as a strategy, they retrieve words that come closer to the desired stimulus ${ }^{5,16}$. Another analysis perspective concerning the students' substitutions suggests that some pictures used in the test can lead to substitution due to contextual proximity or priority access to specific cultural words ${ }^{6}$. The knowledge about Foods, for instance, is closely related to their family's eating habits and thus also associated with the social context.

The family's socioeconomic level is an influencing factor for vocabulary acquisition, which in turn triggers first the oral and then the written language development. In this context, the sensory experiences from the environment to which the person belongs play an essential role in how the sensory information will be processed, converted into words, and retrieved when using expressive vocabulary ${ }^{26}$. If the child's experiences are limited or inexistent, when they take a naming test, for example, their vocabulary production will be impaired, triggering adjustment behaviors to access the information in the absence of a verbal representativity for the image/picture ${ }^{7,12,27}$.

Regarding Means of Transportation, there was a statistical significance in UWD and ND, with respective higher means for $\mathrm{Gl}$ and $\mathrm{Gll}$ in the processes analyzed. Not designating a word indicates that the child has no mental representation of what they are being presented. Hence, they are not apt to retrieve a stimulus they have not yet acquired. In this context, the perspective of the stimulation is present, strongly mentioned in the literature, aiming to intensify the representativity and amplitude of the children's vocabulary, which will be a crucial and triggering ability when learning to read and write $^{13,24,28}$.

Regarding Toys and Musical Instruments, there was a significance only in UWD, with higher means for GI than for Gll. The inclusion of television, computers, and electronic toys in daily life has brought about great changes. The children who live in this new way 
of playing and interacting with others have their development influenced by the new technologies ${ }^{11}$.

A study verified, among other damages, a language delay caused by exposure to these technologies. It must be considered that vocabulary development depends on biological and cognitive factors and on the environment where the child lives. Hence, vivid communicative interactions are important, in which the family plays an essential role as an active mediator furnishing quality stimuli29.

Thus, the presence of new technologies in children's lives can cause language problems for the lack of a mediator acting on vocabulary acquisition, development, and expansion - in addition to word linkage, which is necessary to form sentences and develop dialogues ${ }^{10,19}$. Such an absence of communicative exchange reflects on a more limited vocabulary production, restricting the possibilities of structured communicative exchanges, which can negatively interfere with the children's process of learning to read and write ${ }^{27}$.

Based on this study's analysis of conceptual fields for schoolchildren with and without difficulties learning to read and write, it is suggested that new analyses be conducted with samples from different socioeconomic levels, with students at the beginning of elementary school, belonging to different learning systems. Hence, it will be possible to take a broader look at the children who begin learning to read and write based on their experiences prior to this process. Broadening the sample may also confirm the characteristics identified in this study, as well as survey other characteristics that could not be outlined in this sample.

\section{CONCLUSION}

The schoolchildren with difficulties learning to read and write, when compared with those who had no difficulties, were more impaired in UWD and had higher indexes in SP and ND. These findings revealed a deficient vocabulary with less amplitude and categorization concerning lexical access and processing in children with difficulties learning to read and write.

The substitution errors made by the students with difficulties learning to read and write indicate a tendency to give a meaning semantically close to the one expected. They also suggest a more limited vocabulary that leads to not naming. The performance obtained in this study can be a marker to identify schoolchildren who need intervention to expand, classify, and apply their vocabulary, as the deficit in this ability can interfere with written language performance.

\section{REFERENCES}

1. Tighes LE, Schatschneider CA. Quantile regression approach to understanding the relations among morphological awareness, vocabulary, and reading comprehension in adult basic education students. J Learn Disabil [journal on the internet]. 2016 [accessed on 2019, December 8]; 49(4):424-36. Available at: https://doi. org/10.1177/0022219414556771

2. Silva C, Pereira FB. Performance in receptive vocabulary and reading comprehension tests in elementary education students. Rev. Psicol. teor. Prat [journal on the internet]. 2019 [accessed on 2020, August 10]; 21(2):277-93. Available at: https://doi.org/10.5935/1980-6906/psicologia. v21n2p277-293

3. Limissuri RCA, Befi-Lopes D. Fonologia e vocabulário na percepção de educadores sobre comunicação de pré-escolares. Rev Bras. Est. Pedag [journal on the internet]. 2009 [accessed on 2020, August 10]; 90(225):348-433. Available at: https://doi.org/10.24109/2176-6681. rbep.90i225.518

4. Kaminski TI, Mota HB, Cielo CA. Consciência fonológica e vocabulário expressivo em crianças com aquisição típica da linguagem e com desvio fonológico. Rev. CEFAC [journal on the internet]. 2011 [accessed on 2020, August 10]; 13(5);813-24. Available at: https://doi.org/10.1590/ S1516-18462011005000019

5. Nóro LA, Mota HB. Relationship between mean length of utterance and vocabulary in children with typical language development. Rev. CEFAC [journal on the internet]. 2019 [accessed on 2020, August 10]; 21(6):e4419. Available at: https://doi. org/10.1590/1982-0216/20192164419

6. Araújo MVM, Marteleto MRF, Schoen-Ferreira TH. Avaliação do vocabulário receptivo de crianças pré-escolares. Est Psicol [journal on the internet]. 2010 [accessed on 2020, August 10]; 27(2):169-76. Available at: https://doi.org/10.1590/ S0103-166X2010000200004 
7. Brancalioni AR, Zauza A, Karlinski CD, Quitaiski LF, Thomaz MFO. Expressive vocabulary performance of students aged from 4 to 5 years attending public and private schools. Audiol Commun Res [journal on the internet]. 2018 [accessed on 2020, August 18]; 23:e1836. Available at: http://dx.doi. org/10.1590/2317-6431-2016-1836

8. Gândara JP, Befi-Lopes DM. Trends on lexical acquisition in children within normal development and children with developmental language disorder. Rev Soc Bras Fonoaudiol. 2010; 15(2):297-304.

9. Barbosa ALA, Soares HB, Azoni CAS. Development of a vocabulary-screening tool for children 3 to 7-years of age. Audiol Commun Res [journal on the internet]. 2019 [accessed on 2020, August 10]; 24:e2131. Available at: https://doi. org/10.1590/2317-6431-2019-2131

10. Teixeira BS, Schiefer AM, Carvalho CAF, Àvila CRB. Listening and reading comprehension and syntactic awareness in reading and writing disorders. Rev. CEFAC [journal on the internet]. 2016 [accessed on 2020, August 18]; 18(6):1370-1377. Available at: http://dx.doi.org/10.1590/1982-021620161862216

11. Sargiani RA, Maluf MR. Language, cognition and early childhood education: Contributions of cognitive psychology and neuroscience. Psicol. Esc. Educ [journal on the internet]. 2018 [accessed on 2020, August 12]; 22(3):477-84. Available at: http://dx.doi.org/10.1590/2175-35392018033777

12. Erbeli F, Hart SA, Taylor J. Genetic and environmental influences on achievement outcomes based on family history of learning disabilities status. J Learn Disabil [journal on the internet]. 2019 [accessed on 2020, August 18]; 52(2):135-45. Available at: https://doi. org/10.1177/0022219418775116

13. Christodoulou JÁ, Cyr A, Murtagh J, Chang P, Lin J, Guarino AJ et al. Impact of intensive summer reading intervention for children whit reading disabilities and difficulties in early elementary school. J Learnin Disabil [journal on the internet]. 2017 [accessed on 2020, August 18]; 50(2):115-27. Available at: https://doi.org/10.1177/0022219415617163

14. Nalom AFO, Soares AJC, Cárnio MS. The relevance of receptive vocabulary in reading comprehension. CoDAS [journal on the internet]. 2015 [accessed on 2020, August 18]; 27(4):333-8. Available at: https:// doi.org/10.1590/2317-1782/20152015016
15. Colombo RC, Cárino MS. Reading comprehension and receptive vocabulary in Elementary School students with typical development. CoDAS [journal on the internet]. 2018 [accessed on 2020, August 12]; 30(4):e201700145. Available at: https://doi. org/10.1590/2317-1782/20182017145

16. Pedrosa BAC, Dourado JS, Lemos SMA. Lexical development, speech language disorders and school performance: literature review. Rev. CEFAC [journal on the internet]. 2015 [accessed on 2017, July 6]; 17(5):1633-42. Available at: https://doi. org/10.1590/1982-0216201517519913

17. Aravena S, Tijms J, Snellings $P$, van der Molen MW. Predicting individual differences in reading and spelling skill with artificial script-based letter-speech sound training. J Learnin Disabil [journal on the internet]. 2018 [accessed on 2020, August 18]; 51(6):552-64. Available at: https://doi. org/10.1177/0022219417715407

18. Befi-Lopes DM, Santos MTM. Vocabulário, consciência fonológica e nomeação rápida: contribuições para a ortografia e elaboração escrita. J. Soc. Bras. Fonoaudiol [journal on the internet]. 2012 [accessed on 2020, August 10]; 24(3):269-75. Available at: http://dx.doi. org/10.1590/S2179-64912012000300013

19. Barbosa VM, Silva C. Correlation between receptive vocabulary skill, syntactic awareness, and word writing. Rev. CEFAC [journal on the internet]. 2020 [accessed on 2020, August 18]; 22(3):e2420. Available at: http://dx.doi. org/10.1590/1982-0216/20202232420

20. Andrade CRF, Befi-Lopes DM, Fernandes FDM, Wertzner HF. Teste de linguagem infantil nas áreas de fonologia, vocabulário, fluência e pragmática ABFW. Carapicuiba: Editora Pró- Fono; 2002.

21. Schiff R, Ben-Shushan YN, Ben-Artzi E. Metacognitive strategies: a foundation for early word spelling and reading in kindergartners with SLI. J Learn Disabil [journal on the internet]. 2017 [accessed on 2017, August 12]; 50(2):143-57. Available at: https://doi. org/10.1177/0022219415589847

22. Souza CA, Escarce AG, Lemos SMA. Reading competence of words and pseudo words, school performance and listening skills in primary schools. Audiol Commun Res [journal on the internet]. 2019 [accessed on 2020, August 10]; 24:e2018. Available at: https://doi.org/10.1590/2317-6431-2018-2018 
23. Willoughby MT, Magnus B, Vernon-Feagans L, Blair CB. Developmental delays in executive function from 3 to 5 years of age predict kindergarten academic readiness. J Learn Disabil [journal on the internet]. 2017 [accessed on 2020, August 18]; 50(4):359-72. Available at: http://dx.doi. org/10.1177/0022219415619754

24. Silva C, Capellini SA. Comparison of performance in metalinguistic tasks among students with and without risk of dyslexia. J. Hum. Growth Dev [journal on the internet]. 2017 [accessed on 2020, August 12]; 27(2):198-205. Available at: https://doi. org/10.7322/jhgd.118823

25. Silva C, Capellini SA. Efficacy of phonological intervention program in students at risk for dyslexia. Rev. CEFAC [journal on the internet]. 2015 [accessed on 2020, August 18]; 17(6):1827-37. Available at: https://doi. org/10.1590/1982-021620151760215

26. Conti-Ramsdena G, Durkin K. What factors influence language impairment? Considering resilience as well as risk. Folia Phoniatr Logop [journal on the internet]. 2015 [accessed on 2020, August 12]; 67:293-9. Available at: https://dx.doi. org/10.1159/000444750

27. Dias NM, Bueno JOS, Pontes JMM, Tatiana P. Oral and written language in infant education: relation with environmental variables. Psicol. Esc. Educ [journal on the internet]. 2019 [accessed on 2020, August 10]; 23:e178467. Available at: https:// dx.doi.org/10.1590/2175-35392019018467

28. Carretti B, Motta E, Re AM. Oral and written expression in children with reading comprehension difficulties. J Learn Disabil [journal on the internet]. 2016 [accessed on 2020, August 10];49(1):65-76. Available at: https://doi. org/10.1177/0022219414528539

29. Fink K, Mélo TR, Israel VL. Technologies in neuropsicomotor development in schools four to six years. Cad. Bras. Ter. Ocup [journal on the internet]. 2019 [accessed on 2020, August 10]; 27(2):270-8. Available at: https://doi.org/10.4322/2526-8910. ctoao1186 